\title{
Teaching Philosophy and Its Embodiment
}

\author{
Xinyu Ma \\ Shandong University of Technology \\ Zibo 255049, Shandong, China \\ Tel: 086-533-8303331Ｅ-mail: maxinyu@sdut.edu.cn
}

\begin{abstract}
In order to encourage students to think actively and practice hand-on activities in class, this article reviews some common sense and needed technique in teaching and proposes some teaching philosophy. It also demonstrates observed differences between Chinese students and western students. Its goal is to encourage all of the teachers to revisit the reasons why and the purposes behind daily actions in teaching, so as to improve the effect of classroom teaching and to impel teaching reform in China.
\end{abstract}

Keywords: Teaching philosophy, Embodiment, Interaction, Independent thinking

\section{Philosophy of teaching: original and its adjustments}

Some teachers, especially when they begin their teaching career, generally plan to apply the most of systematic teaching philosophy they have learned and practiced before to their teaching work. They personally supposed that only the person who certainly has the virtue of high awareness of knowledge and is a good role model of students can be a qualified teacher. Consequently, in their mind, teacher then should have the capability to behave the responsibility of a good teacher who can adhere to the high teaching standards, deliver lectures with constant enthusiasm, can be the mentor in academic activities and in everyday life of the students, etc. However, when they become a real teacher, they gradually recognize that if they want to be a successful one, they need to do such following things which are much different from what they have supposed.

1) Keen to learn and think. A qualified teacher should have enough information, knowledge and techniques to inform and educate the student. He also should think of abstracting the rules of teaching activities and can learn from experience to improve and enhance subsequent teaching practice. Objectively, the changing environment and students demand teachers who are full of creative, imaginative and flexible ideas.

2) Kindness and easy-going, full of empathy and communication skills. Facing students and to be a good communicator, the teacher should have both common courtesy and peculiar skills of communication facilitating effective conduction of on-class and off-class activities.

3) Be Enthusiastic and professional. Teaching job needs long-term investment of energy and passion. Whenever any lose of focus on lesson or even a little distraction, this could lead to a failed lecture.

4) Adhere to professional ethics. The Code of ethics often rises from consensus of opinion in teaching field which is also regarded as the best way to put heavy responsibility on the teacher to behave themselves ethically. A good teacher is expected to have the sensitive consciousness on ethical issues and absorb the value of the Code.

To summarize from the above assumptions, a good class or seminar should be organized well and the organizer, ordinarily the teacher manages the whole process in which they plan, prepare, deliver, assess and reflect the session. That also means the teacher should be all-around in the field of teaching. Thus, they need to behave both professionally and comprehensively I believe.

Based on the above thoughts, a supposed scenario of teaching activity according to the best practice as the teaching plan is described:

1) Learning to improve. To learn from the excellence of teaching practice and from one's own experience so teachers can develop the ability on self-correction to make improvement from time to time;

2) Making information transparent. That means teachers understand very well the knowledge which they are going to deliver to students and they can choose the best way to do so taking account of the expectation and special needs from students;

3) Conveying feelings of empathy to create positive environment for student and to inspire students to learn. This is the point emphasized in teaching philosophy; 
4) Two-way teaching: Responsive and responsible and making students and teacher can learn from both sides. Interaction in teaching activity is substantial to involve students to think and the students are willing to do so if the teacher is responsive who can help them to foster good habits and be useful for their future career. At the same time, objective and responsible assessment is another aim for teachers to reach because it should be an important part of the teaching circle;

5) Successful in other roles of a teacher, such as a researcher, a personal tutor. Teachers are often required to make efforts to be diligent in research work and to actively assume responsibility for being a personal tutor.

6) Encourage students to show their personality, characteristics, independent attributes, and freedom spirits.

\section{Comparison of teaching: from the point of students in Western Schools and in China}

I have observed a large amount of differences between students from the western countries and from China. The differences include the teaching philosophy, the organization of a class, the resources lecturer use to deliver lectures. Among the differences, the student-centered teaching philosophy impressed me most.

First of all, the curriculum in the western countries is designed for the benefit of students. The time span only lasts 3 years for an undergraduate student. Most of the courses are designed very close to practice. The content of a course can be rearranged by the lecturer to different levels suitable for students with different aims. For those who would like to take part in practice and develop their career, the content could be easier and more practical while for those who have potential to go further academically, the content could be more attractive and could provoke their interests and creative thinking. In contrast, a lot of curriculums, even some majors in China, are not popular due to their lack of relevance to the real world and are not constructive for the students' profession. Some students choose a career which has nothing to do with their subjects they have learnt before.

Furthermore, the lecturers concentrate the main ideas of a course. This practice makes the lectures clear and condensed and the students can get more time to understand the materials and to get hands on practice of what they have learnt. On the other hand, Chinese students were expected to pay more attention to memorizing and repetition of the things they were delivered. Obviously, to some extent, this will make a lack of independent study and problem-solving ability.

In presenting a lecture, the lecturer usually involve the students thinking about the things they are focusing on and encourage them to question at anytime or at the exclusive question time. Under that scenario and atmosphere, the interests and anxiety to learn can be fully awakened and encouraged. Obviously, both the delivering and organization of the class need a student-centered guideline of teaching.

Guest lecturers in some special fields are always available to give a short talk or a full lecture throughout the course session if necessary which I think is quite good for students to get a better understanding of what they are studying. Courses having their own guest lecturer(s) to give at least one lecture relating to or being a part of the course may be another reflection of linking theory with practice.

Computerized teaching system is widely used where lecturers can put all their software versions of course outlines, course outcome and other requirements, through which they can also announce the information the students need and the students, in return, can hand in their work and propose any questions which can be replied in real time on line. The application of these advanced systems has not reduced the contact between lecturers and students because they are used as an efficient subsidiary tool to normal lectures and face to face tutorials which is quite convenient and effective.

Tutorial time for any questions for all the students was usually set aside in lecturers' office hour regularly. That remind me my experience that seldom tutorial have been done and surely it was quite bad for the courses and for the students. We should learn from this arrangement and put this plan to practice.

With regard to workshops, China and western countries are alike as a rule in that they both give the students a good chance to question, to practice, to do research and to exchange ideas with others.

Independent thinking is another aspect to be cultivated in education system I have noticed. Nevertheless, in China, this is on paper only. Rote learning is still the main approach to receive knowledge though independent thinking has been advocated for a long time. On one hand, the highlighted plagiarism code, lectures focusing on the main ideas of a course, projects connecting to specific topic, individual tutorial support are the main source for students here to be encouraged mentally to a large extent. On the other hand, I find the big difference is that a great number of students never work hard during the semester and they expect to pass the final examinations by fluke or by cheating.

Plagiarism is always thought to be a serious and fatal topic. The intellectual property has gained deserved respect and protected in western countries as we know. Also in the normal exercises, teachers should always emphasize the quotation and plagiarism issue and several lectures mainly about this topic should be set. All these items could make sense to students that they should be very strict to use quotation correctly and note that avoiding plagiarism should become second nature in their life. 
Continuous assessment, not broken assessment, should be available for evaluating the performance of a student which can give the students more objective reflection and long-term encouragement. Examination usually is stressful to the students and it is then not suitable to be the only gauge to assess the subjects. The examination is intended to test the efficiency not the proficiency of the candidates and the 'pass' result means they basically know some special issue and can be able to solve relevant problems in this area. In contrast, the assessment system in China is enormously different in that it usually only focuses on the last phase or final scores of a student. It is an actual fact that all the possible types of assessment, report/thesis, presentation in teams, personal journal, short test which often takes place in the half way through a semester, field works, final test of open book, project, etc., have been employed effectively.

\section{Conclusion}

Most of the teaching philosophy involved in this paper are restated or summarized below:

1) Curriculum structure for a special subject. What kinds of courses should contained in a scheme. Emphasis on the close relationship between theory and practice is realized.

2) Planning a lecture. What type and how many materials should be used in lecture to make the content transparent and easy to understand.

3) Lecture delivering. What resources the lecturer should use to serve the content.

4) Workshop and Tutorial. The tasks set for workshop and the organization of a workshop in accounting subject. How many hours on tutorial a course should have and the conduct of the tutorial session.

5) Assessment and reflection. Possible methods including thesis/report, presentation, test, etc have been used to assess a student continuously throughout their attendance. Impartial reflection on students' performance is needed.

6) Encouragement and support. Support students to be confident and competent in academic study and practical fields.

7) Student-centered teaching and students' team-working, which are to develop skills such as analysis and critical evaluation which is fundamental to the team-working process. Those situations described in teamwork theory are often met in student learning process, problem solving and any other circumstances need more than one person to fulfill. Thus the induction course of teamwork is closely connected to all of us in the teaching activities, the reflective processes and personal development;

Indeed, much further discovery and research are needed to understand the relationships between teacher and students, teaching philosophy and teaching activities. In the facially procedural teaching activities, we embody the philosophy to better deliver the curriculum and get a satisfactory result of teaching.

\section{References}

Bland Tomkinson. (2006). Reflective Practice. Lecture handout.

Morkuniene, Jurate. (2005). The problelm method in teaching philosophy: a praxiologic educology. Online Submission, cd-International Journal of Educology, Spec Iss.

Roever, Carol. (2008). Teaching philosophy: reflections by the 2007 ABC outstanding teacher. Business Communication Quarterly. 711.

Worsfold, Victor L. (2001). Teaching philosophy of education today. Educational Theory, 51, 3. 